\title{
GEOPOLYMER CEMENTS AND THEIR PROPERTIES: A REVIEW
}

\author{
VLADIMÍR ŽIVICA, MARTIN T. PALOU, MARTIN KRIŽMA
}

\begin{abstract}
Concrete is the world's most versatile, durable and reliable construction material. Next to water, concrete is the second most used substance on earth and it requires large quantities of Portland cement. The industrial sector is the third largest source of man-made carbon dioxide emissions after the transportation sector as the major generator of carbon dioxide, which pollutes the atmosphere. Ordinary Portland cement (OPC) production produces the largest amount of carbon dioxide amongst all industrial processes. In addition to that a large amount of energy is also consumed for the cement production. The production of OPC not only consumes a huge amount of the natural resources i.e. limestone and fossil fuels but also produces almost $0.9 \mathrm{t}$ of $\mathrm{CO} 2$ for $1 \mathrm{t}$ of cement clinker production. Thus, the world cement production generates 2.8 billion tons of manmade greenhouse gas annually. Hence, it is inevitable to find an alternative material to the existing most expensive, most resource and energy consuming Portland cement.

Geopolymer cements are innovative binders which can be produced by the chemical action of aluminosilicate materials plenty available worldwide. They are rich in silica and alumina reacting with alkaline solution and producing aluminosilicate gel that acts as the binding material for the concrete. Geopolymers are synthesized by polycondensation reaction of geopolymeric precursor and alkali polysilicates.

The paper presents data on the important engineering properties of geopolymer cements showing that these cements offer an alternative to, and potential replacement for, OPC. Geopolymer technology also has the potential to reduce global greenhouse emissions caused by OPC production. Due to the high level of mechanical properties of geopolymer cements and their environmentally beneficial technology they appear as a prospective construction material for the future.
\end{abstract}

Keywords: geopolymer cement, ordinary Portland cement, technology, properties

\section{Introduction}

Manufacturing of Portland cement is a resource exhausting, energy intensive process that releases large amounts of the green house gas $\mathrm{CO}_{2}$ into the atmosphere. A production of 1 ton of Portland cement requires about 2.8 tons of raw materials including fuel and other materials. As a result of de-carbonation of lime, manufacturing of 1 ton of cement generates about 1 ton of $\mathrm{CO}_{2}$. At present, efforts have been made to promote the use of pozzolans to partially replace Portland cement. Recently another class of cementitious materials, produced from aluminasilicate precursor activated in high alkali solution-geopolymers, has been developed (Guo et al, 2010).

Institute of Construction and Architecture, Slovak Academy of Sciences, Dúbravská cesta 9, 84503 Bratislava 45, Slovak Republic, e-mail: vladimir.zivica@savba.sk, martin.palou@savba.sk, martin.krizma@savba.sk 
Geopolymer cements are a new type of inorganic cementitious materials. They synthesize under the alkali-activation produced geopolymers having binding ability and therefore they can be used as a potential alternative to some conventional construction materials, e. g. Portland cement. Recently this material has been extensively studied due to its exceptional mechanical, chemical, and physical properties and potentially broad practical application in civil infrastructure construction, waste encapsulation, and sustainable development (Guo et al., 2010; Al Bakri et al., 2010; Kong and Sanjayan, 2008; Lodeiro et al., 2007; Davidovits, 1994).

\section{Properties of geopolymer cements}

According to the reaction process, two factors have a direct effect on the final product, namely, the aluminosilicate and activator. Properties of the solid aluminosilicate will directly affect the dissolution process and the subsequent reaction, while the liquid activator will partially or completely dissolve the solid raw material and determine break and recombination of the aluminosilicate structure, polycondensation and charge balance in the reaction system (Duxson et al., 2005).

The properties of the hydration products of geopolymers are strongly affected by the type of activator; the activator anion plays an important role in microstructural development.

The sodium hydroxide, silicate, carbonate and sulphate, sodium hydroxide and sodium silicate are the more commonly used alkaline activating agents. A few studies have also been carried out with potassium hydroxide or sodium carbonate as the activating agent ( $\mathrm{Li}$ et al., 2005; McLellan et al., 2011; Gum et al., 2013; Temuujin et al., 2010).

Geopolymers have also been shown to exhibit superior mechanical properties to those of Ordinary Portland Cement (OPC). They are the results of the hardening of the alkali activated aluminosilicate constituent of the binding system and the action of the technologic conditions of the hardening (Davidovits, 1989; Davidovits, 1991; Fletscher et al., 2005; Buchwals et al., 2004; Duxson et al., 2007; Xu and van Deventer, 2000; Zhang and Gambrell, 2010).

Geopolymers exhibit a wide range of properties and characteristics that make them suitable for diverse applications, depending on the raw materials used in polymer synthesis (Kaps and Buchwald; 2002; Živica, 1993). In fact, the starting raw materials play a vital role in the geopolymerisation reactions and control the chemical composition and microstructure of the final geopolymeric products.

Geopolymers have received considerable attention because of their low cost, excellent mechanical and physical properties, low energy consumption and reduced "green house emissions" during the elaboration process (Hua and van Deventer, 2003; Phair and van Deventer, 2001; Živica, 1993; Živica, 1999; De Silva et al., 2007; Rowles and Connor, 2003).

\section{Processing factors}

A considerable number of variables are involved in alkaline activation, most prominently the composition of the prime materials (particle size, vitreous phase content, silica and reactive alumina content); type and concentration of the alkaline activator; liquid/solid ratio; curing temperature and time; and moisture conditions during initial curing. These variables have been amply studied in the literature because they affect the degree of reaction, the mineralogical composition and microstructure of the reaction products and ultimately the physical-mechanical properties of the material. 


\subsection{Materials}

Most waste materials such as fly ash, blast furnace slag and mine tailings contain sufficient amounts of reactive alumina and silica that can be used as source materials for in situ geopolymerisation reactions (Weil et al., 2007; Duxson et al., 2005; Duxson et al., 2007). Nevertheless, the most studies have used the source materials on an arbitrary basis without consideration of the mineralogy or paragenesis of the individual minerals.

It is important to note that the interrelationship between mineralogy and reactivity of individual minerals is extremely complex, and so further research on the ability of a wide variety of different materials to undergo geopolymerisation is required in order to elucidate the underlying chemical mechanisms. It is reasonable to assume that the type and nature of the starting materials used will directly affect the final physical and chemical properties of a geopolymer derived from waste materials. The current work therefore investigates the effect of various compositions of fly ash and kaolinite mixes on the physical and chemical properties of geopolymers.

It was shown that the water content, curing as well as calcining conditions affect the final properties of a geopolymer.

\subsection{Type and concentration of activator}

Effect of type and concentration of activator is based on the resulting solubility of the materials. The solubility of these materials varies depending on the $\mathrm{pH}$ of the activating solutions. Solubility is high in acid media, but the instability of the resulting hydrates prevents any cementitious structure forming. By contrast, at basic $\mathrm{pH}>11$ the material dissolves and forms stable hydrates, with a gradual increase in the binding properties of the material (Abdullah et al., 2011).

The most widespread opinion around activator concentration is that the higher it is the greater is mechanical strength of the material. Nonetheless, this is not completely accurate, but depending in part on the activator used, there may be certain threshold values above which the strength does not rise significantly, or may even fall. Moreover, these high doses of alkalis may have adverse effects, increasing efflorescence, brittleness and so on. Nor should the economic factor be overlooked, for higher doses entail higher costs. When deciding which activator to use, however, mechanical strength should not be the only criterion considered. Other properties of importance in this regard include durability (resistance to acid, carbonation, the silica-alkali reaction), fire resistance, matrix-steel bonding, drying shrinkage and so on (Abdullah et al., 2011; Duxson et al., 2005; Granizo and Blanco, 1998).

In (Abdulkareem et al.; 2013 and Shi et al., 2006) a high effective activator based on the silica fume is shown. Its effectiveness is shown in Figure 1.

\subsection{Curing conditions}

The temperature and curing time enhance mechanical strength, particularly early age strength, improves durability, and limits product fluctuations and efflorescence. Increasing the temperature during initial curing accelerates the reaction rate of these materials. As in the case of Portland cement, higher temperatures may have both beneficial and adverse effects on mechanical strength development in geopolymer cements. The hydration products formed are generally amorphous, although rising temperatures may on occasion lead to the formation of crystalline products (Alonso and Palomo, 2001; Palomo and Fernandez - Jiménez, 2005). 


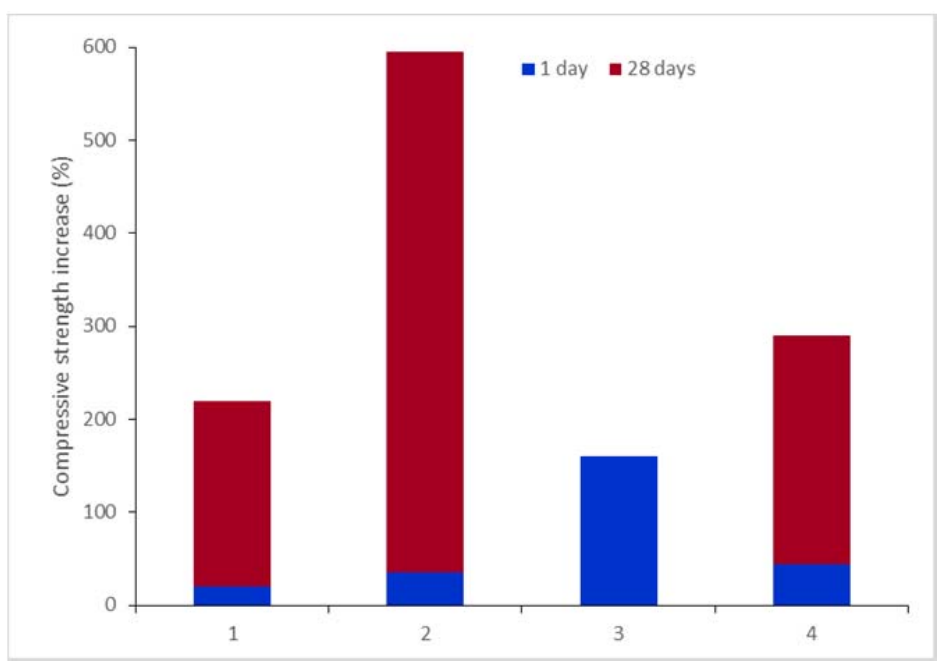

Figure 1. Comparison of the effectiveness of the alkali activator used: 1 . Slag + silica fume activator substituted for sodium hydroxide; $2.30 \%$ Portland cement $+70 \%$ slag + silica fume activator substituted for water; 3. $10 \%$ Portland cement $+90 \%$ slag + silica fume activator substituted for water, 1 and 28 days values are equal; 4. Slag + silica fume activator substituted for water glass (Živica, 2004)

A curing temperature is the most important factor. As the curing temperature increases, the setting time decreases, and compressive strength increases. The curing temperature within $60-90{ }^{\circ} \mathrm{C}$ range, curing time in range of $24 \mathrm{~h}-72 \mathrm{~h}$ and compressive strength between $40-50 \mathrm{MPa}$ seem to be optimal (Živica, 1999). Mild curing seems to improve physical properties while curing under higher humidity is not usually beneficial. Rapid curing and/or curing at too high temperatures will result in cracking and thus have a negative effect on physical properties. The current work has therefore shown that the manufacture of a geopolymer product for specific applications requires careful consideration of process conditions such as curing temperature and humidity, in addition to the initial mix design.

\subsection{Water/binder ratio}

The dependence of the engineering properties of concretes and other cement composites on the value of water/cement ratio (w/c) is very well known. Also it is the fact that their strengths, durability and the quality of other engineering properties are increased when the w/c ratio values are decreased (Živica, 2004; Fernández et al., 2005; Fernández et al., 2009).

A significant factor limiting the use of these positive effects is that by the decrease of the w/c ratios, the workability of the fresh composite mixture and the resulting engineering properties of the hardened composite are decreased. A limited solution is enabled by the use of the plasticizers or the superplasticizers. A very attractive solution represents the combination of super low $\mathrm{w} / \mathrm{c}$ ratios, under $\mathrm{w} / \mathrm{c}=0.1$ and high pressure compaction (Chanh et al., 2008; Schulze, 1999; Naragaj and Zahida Banu, 1996; Appa Rao, 2001; Freidin, 2007; Zhongzi et al., 1993 a; Zhongzi et al., 1993 b; Roy et al., 1972).

Figure 2 presents the effects of w/c ratio and applied pressure on compressive strength and total porosity of the cement paste. 


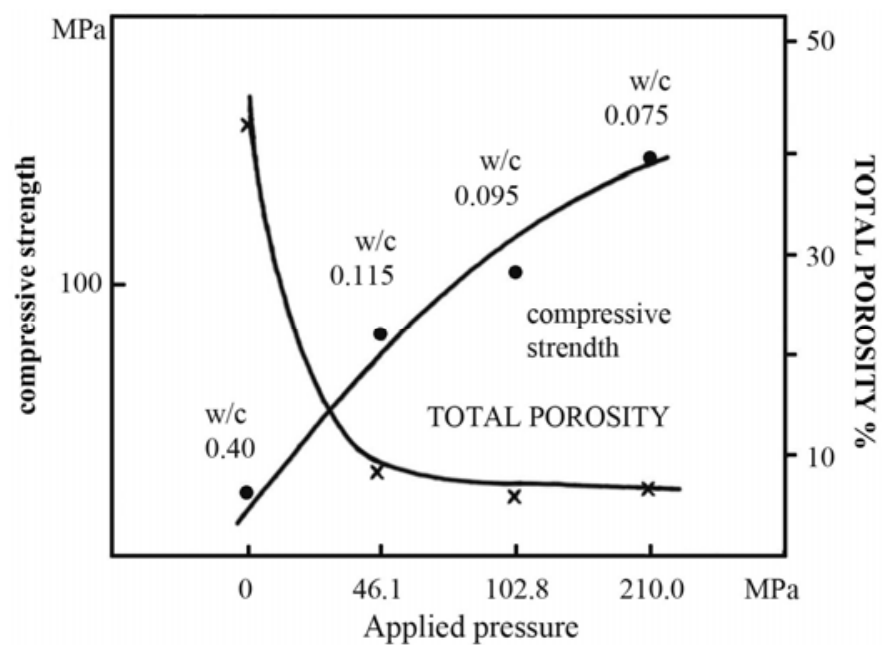

Figure 2. Dependence of compressive strength and total porosity of cement pastes on w/c ratio and applied pressure after 1 day of hardening

\section{Geopolymer cements preparation}

Geopolymers are a class of inorganic polymers formed by the reaction between an alkaline solution and aluminosilicate materials. The reactants are an alkali metal hydroxide/silicate solution and an aluminosilicate binder. Commonly used binders include fly ash, ground granulated slags or metakaolin, but any fine amorphous aluminosilicate material can be used. Most waste materials such as fly ash, blast furnace slag and mine tailings contain sufficient amounts of reactive alumina and silica that can be used as source materials for in situ geopolymerisation reactions. One condition is the presence of amorphous alumina silicates and $\mathrm{SiO}_{2}+\mathrm{Al}_{2} \mathrm{O}_{3}>80 \mathrm{wt} \%$ content (Weil et al., 2007; Duxson et al., 2005 and 2007; Gasteiger et al., 1992).

To produce geopolymer from kaolin or other clay materials three main steps are necessary:

(i) thermal activation, the aim of which is to obtain a clay material with a high chemical activity.

In this process dehydroxylation of clay mineral leads to an unstable amorphous solid,

(ii) alkali activation: an activated alumino-silicate material is dissolved in a highly alkaline solution to produce silicate and aluminate monomers (Xu and van Deventer, 2000),

(iii) reactive setting or polycondensation, in which the silicate and aluminate monomers condense to a stable polymer network (Davidovits, 1991). The polymerisation process involves a substantially fast chemical reaction under alkaline condition on Si-Al minerals that results in a three dimensional polymeric chain and ring structure consisting of Si-O-AlO bonds.

To obtain a well structured geopolymer with acceptable mechanical properties, it is necessary to enhance the activity and solubility of Al-Si source materials in alkali solution. Thermal activation of the source material is one way to meet this condition effects on final properties (Kaps and Buchwald, 2002).

The common materials used as alkaline solution in producing geopolymer are sodium and potassium hydroxide. Chindaprasirt et al. (2007) found out that, to produce higher strength 


$$
\begin{aligned}
& \mathrm{KOH}, \mathrm{NaOH} \\
& \left(\mathrm{Si}_{2} \mathrm{O}_{5}, \mathrm{Al}_{2} \mathrm{O}_{2}\right) n+\mathrm{H}_{2} \mathrm{O} \quad \rightarrow \quad n(\mathrm{OH})_{3}-\mathrm{Si}-\mathrm{O}-\mathrm{Al}(\mathrm{OH})_{3} \\
& \mathrm{KOH}, \mathrm{NaOH} \\
& n(\mathrm{OH})_{3}-\mathrm{Si}-\mathrm{O}-\mathrm{Al}(\mathrm{OH})_{3} \quad \rightarrow \quad(\mathrm{Na}, \mathrm{K})(-\mathrm{Si}-\mathrm{O}-\mathrm{Al}-\mathrm{O}) n+3 n \mathrm{H}_{2} \mathrm{O} \\
& \text { (Orthosialate) } \\
& \mathrm{O} \mathrm{O} \\
& \downarrow \\
& \left(\mathrm{Si}_{2} \mathrm{O}_{5}, \mathrm{Al}_{2} \mathrm{O}_{2}\right) \mathrm{n}+\mathrm{nSiO}_{2}+\mathrm{nH}_{2} \mathrm{O} \quad \rightarrow \quad n(\mathrm{OH})_{3}-\mathrm{Si}-\mathrm{O}-\mathrm{Al}-\mathrm{O}-\mathrm{Si}-(\mathrm{OH})_{3} \\
& \mathrm{KOH}, \mathrm{NaOH} \\
& n(\mathrm{OH})_{3} \text {-Si-O-Al-O-Si- }(\mathrm{OH})_{3} \quad \rightarrow \quad(\mathrm{Na}, \mathrm{K})(\mathrm{Si}-\mathrm{O}-\mathrm{Al}-\mathrm{O}-\mathrm{Si}-\mathrm{O}-) n+n \mathrm{H}_{2} \mathrm{O}
\end{aligned}
$$

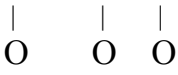

$$
\begin{aligned}
& \text { Oligo (sialate-siloxo) } \\
& \text { (Na, K)-poly(sialate-siloxo) } \\
& \text { Polymerzation reactions } \\
& \text { Poly(sialate) }\{\mathrm{Si}: \mathrm{Al}=1(-\mathrm{Si}-\mathrm{O}-\mathrm{Al}-\mathrm{O}-)\} \\
& \{\mathrm{Si}: \mathrm{Al}=2(-\mathrm{Si}-\mathrm{O}-\mathrm{Al}-\mathrm{O}-\mathrm{Si}-\mathrm{O})\} \\
& \text { Poly(sialate-disiloxo) } \\
& \{\mathrm{Si}: \mathrm{Al}=3 \text { (-Si-O-Al-O-Si-O-Si-O) }\}
\end{aligned}
$$



$$
\begin{aligned}
& \begin{array}{lll}
\mathrm{O} & \mathrm{O} & \mathrm{O}
\end{array} \\
& \text { O-Si-O-Al-O-Si-O } \\
& \begin{array}{lll}
\text { O } & \text { I } & \text { I }
\end{array} \\
& \begin{array}{llll}
\mathrm{O} & \mathrm{O} & \mathrm{O} & \mathrm{O}
\end{array} \\
& \text { O-Si-O-Al-O-Si-O-Si-O } \\
& \begin{array}{llll}
\text { l } & \text { l } & \text { l } & \text { l } \\
\mathrm{O} & \mathrm{O} & \mathrm{O} & \mathrm{O}
\end{array}
\end{aligned}
$$
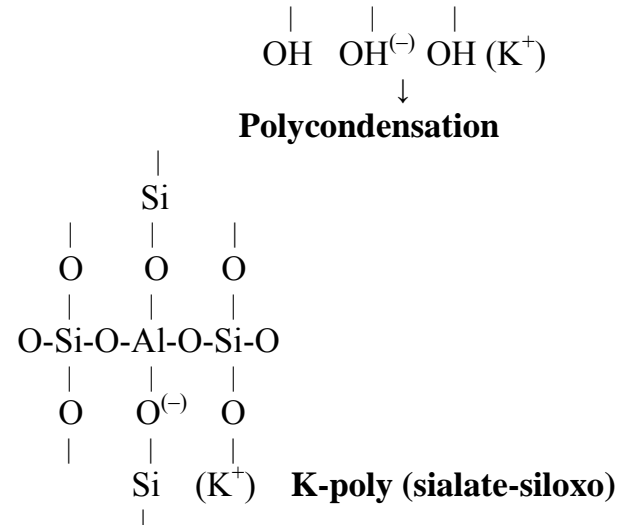

Figure 3. Polymerization reaction (Appa Rao, 2001) 
geopolymer, the optimum sodium silicate to sodium hydroxide ratio is in range of 0.67 to 1.00 . Meanwhile, the concentration of $\mathrm{NaOH}$ between 10 and $20 \mathrm{M}$ gives a small effect to the strength.

Previous studies have shown that the amount of vitreous silica and alumina present in the starting material plays a significant role in activation reactions and the properties of the reaction product (Hongling et al., 2005; van Jaarsveld et al., 2003).

A clear representation of the chain reaction involved during the polymerization is shown in Figure 3.

All mentioned dependences and effects are common also to geopolymer systems distinguished from the related cement materials only by the specific properties of geopolymer as a binder. The significance of the water/OPC ratio for the geopolymer systems is reported by Barbosa et al. (2000). According to the authors the effects of the changes of water/cement ratio on the properties of the geopolymers are the same as at cement materials. Similar is the effect of ambient temperature increase showing the setting time decrease as a consequence of the increase of rapidity of polymerization. But only the temperature increase to $90^{\circ} \mathrm{C}$ seems to be optimal (Durekovic, 1995; Roessler and Odler, 1985; Farah et al., Barbosa et al., 2000; Cindaprasirt et al., 2007). Using a combination of the low w/c ratio and pressing technology it was possible to reach $75-150 \mathrm{MPa}$ compressive strength of metakaolin, metahalloysite and slag based geopolymers (Chang et al., 2008; Kong and Sanjanyan, 2010 a; Kong and Sanjanyan, 2010 b; Rodríguez et al., 2013; Živica et al., 2010; Živica et al., 2011). Table 1 affords an illustration of the results.

Table 1. Bulk density, compressive strength and pore structure parameters of metakaolin based geopolymer pastes after $24 \mathrm{~h}$ of hardening (Živica et al., 2011)

\begin{tabular}{|l|c|c|c|c|c|}
\hline Paste & $\begin{array}{c}\text { Bulk density } \\
(\mathrm{kg} \mathrm{m}-3)\end{array}$ & $\begin{array}{c}\text { Compressive } \\
\text { strength } \\
(\mathrm{MPa})\end{array}$ & $\begin{array}{c}\text { Total } \\
\text { porosity } \\
(\%)\end{array}$ & $\begin{array}{c}\text { Pore } \\
\text { median } \\
(\mathrm{nm})\end{array}$ & $\begin{array}{c}\text { Specific } \\
\text { surface area } \\
\left(\mathrm{m}^{2} \mathrm{~g}-1\right)\end{array}$ \\
\hline $\begin{array}{l}\text { Pressure } \\
\text { compacted }\end{array}$ & 1862 & 146.6 & 15.7 & 59 & 5.5 \\
\hline Reference & 814 & 0.03 & 54.5 & 814 & 5.8 \\
\hline
\end{tabular}

\section{Properties of fresh mixture}

The rheologic properties of fresh mixtures, mainly their flowability or workability respectively and setting rate are very significant for the practical application of cement materials (Živica et al., 2014). While the rheological behaviour of Portland cement pastes and mortars has been investigated in depth, the rheology of geopolymer materials has not yet been explored, despite the importance of such research for an understanding and explanation of the behaviour of these cements and concretes during on-site placement (Barger et al., 2001). Consequently, one of the objectives of research should be to understand the rheological behaviour of geopolymer cement pastes and mortars in relation to the effect of the activator nature on their rheology.

The significant rheological properties of the fresh geopolymer mixtures are workability and setting, depending strongly also on the quantity of water added. This quantity or water/binder 
ratio (w/b) significantly influences the workability of the mixtures, their setting but even the engineering properties of the hardened products (Valeria et al., 2000; Gurley, 2003; Nicholson et al., 2005; Benfill, 2006).

The setting rate represents a very important property of the fresh geopolymer mixtures influencing the time interval needed for the possibility of their placing in situ.

As it can be found in the literature the setting rate and control of these systems seems to be problematic. For instance the fly ash as a component of geopolymer can show extremely short setting times on activation by alkaline silicate solution due to its high lime content. This limits the commercial exploitation of the fly ash as a raw material for geopolymers (Schulze, 1999).

The uncontrolled setting exhibited by waterglass-activated slag pastes and mortars is due to the formation of a primary C-S-H gel in the early stages of the reaction as a result of the bonding of the $\mathrm{Ca}^{2+}$ ions present in the slag to the silicate ions in the waterglass solution (Duxson et al., 2005, Duxson et al., 2007). However, no solution for controlling setting in these cements or for improving their workability has been put forward to date Appa Rao, 2001; Jambor, 1990; Palacios, 2006; Nicholson and Shimada, 2005; Chang, 2003).

Nicholson et al. (2005) have shown that addition of inorganic boron to the activator solution not only significantly extend setting times, but also allows a predefined setting time to be achieved by varying the amount and source of boron added. Subsequent characterisation of the products indicates that the boron is structurally incorporated in the matrix, giving rise to a novel class of boroaluminosilicate geopolymers (Schulze, 1999).

\section{Properties of hardened geopolymer cements}

\subsection{Strength}

Mechanical behaviour is a basic property in assessing an engineering material for a specific application. For geopolymers as novel cementitious materials, the compressive strength is an important factor. Ever since their invention in the 1970s the better compressive strength, setting time and durability of geopolymers over conventional cements have been perceived as advantages. However, the compressive behaviour of geopolymers varies according to the raw materials and processing method used. To obtain a geopolymer with high compressive strength, a high strength gel phase and high ratio of gel to non-polymeric phases are required. These factors relate directly to the type and molar ratios of oxides in the Al-Si source, type and $\mathrm{pH}$ of alkali solution and solubility of raw materials in the activator solution (Fernandez-Jimenez and Puertas, 2003; Palacios et al., 2008; Quing-Hua and Sarkar, 1994; Chindaprasirt et al., 2007).

In view of the importance of the dissolution of Al-Si species in alkali solution and of the polymerisation reaction, it is unsurprising that the characteristics of the alkali solution directly affect the microstructural reorganisation of the calcined clay and so the final mechanical properties of the product. It has been shown that flexural strength, compressive strength and apparent density of geopolymers increase as $\mathrm{NaOH}$ solution concentration increases. Using alkali solution composed of alkali hydroxide and dissolved silicate has been found to be beneficial for compressive strength relative to alkali hydroxide alone.

\subsection{Durability}

High resistance of geopolymer cements against aggressive environment is reported in many papers. The following ones are presented as examples (Davidovits, 1994; Thokchom et al., 2010; Xu, 2002; Živica and Križma, 2013). Fly ash-based geopolymer cement had been proved 
by many studies to provide better resistance against aggressive environment. According to Bakharev (2005) in acidic exposure, high-performance geopolymer materials deteriorate with the formation of fissures in amorphous polymer matrix, while low-performance geopolymers deteriorate through crystallisation of zeolites and formation of fragile grainy structures. The formation of aluminosilicate gel is important to determine the stability of geopolymer. More crystalline geopolymer material prepared with sodium hydroxide was more stable in the aggressive environment of sulfuric and acetic acid solutions than amorphous geopolymers prepared with the sodium silicate activator (Davidovits, 1994).

Thokchom et al. (2010) investigated the effect of sodium oxide content on durability of geopolymer in sulphuric acid. Specimens with varying alkali content showed varying degree of deterioration when exposed to sulphuric acid. Besides that, the specimens showed no visible sign of structural disintegration but under optical microscope observation, the surface deterioration was clearly visible and it appeared more severe in specimen with less alkali content. The specimen with maximum alkali content showed more reduction in weight compared to minimum alkali content. On the other hand, specimen with minimum alkali content lost more strength. Hence, specimen a with higher alkali content performed much better, than those with a lower alkali content in terms of residual compressive strength (Thokchom et al., 2010).

Interesting high acidic resistance of geopolymer was reached when silica fume activator was used (Xu, 2000; Živica and Križma, 2013).

A general fire resistance of geopolymer cements is reported. It was found that the fly ashbased geopolymer displayed increase in strength after temperature exposure. Kong and Sanjayan (2008) observed that the behaviour of geopolymer concrete under elevated temperature was affected by the size of aggregates. The aggregate of a smaller size $(<10 \mathrm{~mm})$ could lead to spalling and also extensive cracking of geopolymer but the larger aggregate $(>10$ $\mathrm{mm}$ ) were more stable. In addition, the thermal incompatibility between the geopolymer matrix and its aggregate components was the most likely cause of the strength loss in geopolymer concrete specimens at elevated temperatures. It can be proved by comparison of geopolymer concretes made with two different aggregates of distinctly different thermal expansion characteristics. The geopolymer concrete with greater incompatibility led to higher strength loss during elevated temperature (Kong and Sanjayan, 2008; Kong and Sanjayan, 2010).

It was observed that the thermal stability of the geopolymer materials prepared with sodium containing activators was rather low and significant changes in the microstructure occurred. The reverse situation was observed when potassium silicate was used as activators because it can remain mostly amorphous up to $1200^{\circ} \mathrm{C}$ (Bakharev, 2006).

Geopolymer cements show high freeze-thaw resistance. Alkali activated slag concrete due to a low water demand and a high electrolyte concentration in the pore solution, can bear $300-1150$ cycles of repeated freezing-thawing, compared with fewer than 300 cycles for normal OPC concretes (Gourley, 2003).

Due to the high alkalinity in geopolymer environment the decreased effects of the carbonation and increased protection effect of the embedded steel reinforcement in the geopolymer cement concrete opposite to the OPC cement can be expected (Pu, 1999; Pandey et al., 2012. 


\section{Applications}

The properties of geopolymers are significanly dependent on the silica/alumina ratio and their specific possibilities of various applications can be seen in Table 2. It is evident that the properties of geopolymers offer broad possibilities of the applications also outwith the binder region

Table 2. Applications of geopolymeric materials according to silica/alumina atomic ratio (Van Jaarsveld et al., 2003)

\begin{tabular}{|c|l|}
\hline Si/Al ratio & Applications \\
\hline \multirow{4}{*}{1} & Bricks \\
\cline { 2 - 2 } & Ceramics \\
\cline { 2 - 2 } & Fire protection \\
\hline \multirow{2}{*}{2} & Low $\mathrm{CO}^{2}$ cements and concretes \\
\cline { 2 - 2 } & Radioactive and toxic waste encapsulation \\
\hline \multirow{4}{*}{3} & Fire protection fibre glass composites \\
\cline { 2 - 3 } & Foundry equipments \\
\cline { 2 - 2 } & Heat resistant composites, $200^{\circ} \mathrm{C}-1000^{\circ} \mathrm{C}$ \\
\cline { 2 - 2 } & Tooling for aeronautics titanium process \\
\hline \multirow{3}{*}{$>3$} & Sealants for industry, $200^{\circ} \mathrm{C}-600^{\circ} \mathrm{C}$ \\
\cline { 2 - 2 } & Tooling for aeronautics $\mathrm{SPF}$ aluminium \\
\hline $20-35$ & Fire resistant and heat resistant fibre composites \\
\hline
\end{tabular}

\section{Future research}

Geopolymer technology is gaining interest because of the successful application of products in various fields, driven by the superior properties of geopolymers relative to currently used materials. In addition, the environmental impact of the production process of Portland cement will drive active consideration of alternatives, including geopolymers.

However, the research community first needs to address existing gaps in the knowledge of geopolymerisation and the properties of geopolymers. The following research seems to be important like: improved characterisation of raw materials appropriate for geopolymerisation, optimised curing conditions - strength relation and data on the response of geopolymeric products to severe environments under creep and fatigue loading. Sound data on the long term behaviour of geopolymers appears to be an important assumption as an intermediate party of their infiltration into practice.

\section{Conclusion}

The presented data on the important engineering properties of geopolymer cements show that these cements offer an alternative to, and potential replacement for, OPC. Geopolymer technology has also the potential to reduce global greenhouse emissions caused by OPC production. Due to a high level of mechanical properties of geopolymer cements and their 
environmentally beneficial technology they appear as a prospective construction material for the future.

This position is substantiated and established by the existing abundant raw materials resources, mainly industrial wastes and simple preparation technique saving energy and environment. The additional significant benefit of geopolymer cements represents their properties which include high early strength, low shrinkage, freeze-thaw resistance, sulfate resistance and corrosion resistance, make them useful for long-term containment of toxic and hazardous wastes. The properties of the geopolymers make them as the material advisable for the application in various branches of industry besides the binder region.

\section{Acknowledgement}

The paper has been produced with the financial assistance of the Slovak grant agency VEGA, grant no. 2/0082/14 and grant no. 2/0143/12.

\section{REFERENCES}

[1] Abdullah, A., Hussin, K., Bnhussain, M., Ismail, K. N. and Ibrahim, W. M. W. (2011), "Mechanism and Chemical Reaction of Fly Ash", International Journal of Pure and Applied Sciences and Technology 6, 35-44.

[2] Abdulkareem, A., Al Bakri Abdullah, M. M., Hussin, K., Ismail, K. N. M. and Binhussain, M. (2013), "Mechanical and Microstructural Evaluations of Lightweight Aggregate Geopolymer Concrete before and after Exposed to Elevated Temperatures", Materials 6, 4450-4461.

[3] Al Bakri, M. M., Mohammed, H., Kamarudin, H., Khairul Niza, I. and Zarina, Y. (2011), "Review on fly ash-based geopolymer concrete without Portland Cement", Journal of Engineering and Technology Research 3, 1-4.

[4] Alonso, S. and Palomo, A. (2001), "Alkaline activation of metakaolin-calcium hydroxide solid mixtures: Influence of temperature, activator concentration and metakaolin $/ \mathrm{Ca}(\mathrm{OH}) 2$ ratio" Materials Letters 47, 55-62.

[5] Appa Rao, G. (2001), "Role of water-binder ratio on the strength development in mortars incorporated with silica fume", Cement and Concrete Research, 31, 443-447.

[6] Bakharev, T. (2005), "Resistance of geopolymer materials to acid attack", Cement Concrete Res. 35, 658-670.

[7] Bakharev, T. (2006), "Thermal behaviour of geopolymers prepared using class F fly ash and elevated temperature curing", Cement Concrete Res. 36, 1134-1147.

[8] Bakri, A. M. Mustafa Al, Liyana, J., Kamarudin, H., Bnhussain, M., Ruzaidi, C. M., Rafiza, A. R. and Izzat, A. M. (2013), "Study on refractory materials application using geopolymer processing", Advanced Science Letters 19, 221-223.

[9] Banfill, P. F. G. (2006), "Rheology of Fresh Cement and Concrete", Rheology Reviews, 61-131.

[10] Barbosa, V. F., MacKenzie, K. J. and Thaumaturgo, C. (2000), "Synthesis and characterisation of materials based on inorganic polymers of alumina and silica: sodium polysialate polymers", International Journal of Inorganic Materials 2, 309-317. 
[11] Barger, G. S., Hansen, E. R., Wood, M. R., Neary, T., Beech, D. J. and Jacquier, D. (2001), "Production and Use of Calcined Natural Pozzolans in Concrete", Cement, Concrete and Aggregates 23, 73-80.

[12] Buchwald, A., Hohmann, M., Kaps, C., Bettziehe, H. and Kuhmert, J. T. (2004), "Stabilized foam clay material with high performance thermal insulation properties", CFI - Ceram Forum Int. 81, E 39-42.

[13] Hardjito, D., Wallah, S. E., Sumajouw, D. M. J. and Rangan, B. V. (2004), "Factors influencing the compressive strength of fly ash-based geopolymer concrete", In Civil Engineering Dimension 6, 88-93.

[14] Chanh, V., Trung, B. D. and Van Tuan, D. (2008), "Recent research geopolymer concrete", The 3rd ACF International Conference-ACF/VCA, 235-241.

[15] Chang, J. J. (2003), "A Study on the Setting Characteristics of Sodium Silicate-Activated Slag Pastes", Cement and Concrete Research 33, 1005-1011.

[16] Chindaprasirt, P., Chareerata, T. and Sirivivatnanon, V. (2007), "Workability and strength of coarse high calcium fly ash geopolymer", Cement and Concrete Composites 29, 3, 224-229.

[17] Davidovits, J. (1989), "Geopolymers and geopolymers materials", J. Therm. Anal. 35, 429-431.

[18] Davidovits, J. (1991), "Geopolymers inorganic polymeric new materials“, J. Therm. Anal. 37, 1633-1656.

[19] Davidovits, J. (1994), "Geopolymer: Man-made rocks geosynthesis and the resulting development of very early high strength cement", J. Mat. Educ., 16, 91-139.

[20] De Silva, P., Sagoe-Crenstyl, K. and Sirivivatnanon, V. (2007), "Kinetics of geopolymerization: Role of $\mathrm{Al} 2 \mathrm{O} 3$ and $\mathrm{SiO} 2 "$, Cem. Concre. Res. 37, 512-518.

[21] Durekovic, A. (1995), "Cement pastes of low water ratio: An investigation of the porosity characteristics under the influence of a superplasticizer and silica fume", Cement and Concrete Research 25, 365-375.

[22] Duxson, P., Provis, J. L., Lukey, G. C., Mallicoat, S. W., Kriven, W.M. and van Deventer, J. S. J. (2005), "Understanding the relationship between geopolymer composition, microstructure and mechanical properties", Colloids and Surfaces A: Physicochemical and Engineering Aspects 269, 47-58.

[23] Duxson, P., Fernandez-Jimenez, A., Provis, J. L., Lukey, G. C., Palom, A. and van Deventer, J. S. J. (2007), "Geopolymer technology: the current state of the art" J. Mater Sci 42, 2917-2933.

[24] Farah, F., Kamarudin, H., Azmi, R., Mustafa Al Bakri and A.M. (2014), "A Study on Relationship between Porosity and Compressive Strength for Geopolymer Paste", Key Engineering Materials 594-595, 1112-1116 11/2013.

[25] Fernandez-Jimenez, A. and Puertas, F. (2003), "Effect of Activator Mix on the Hydration and Strength Behavior of Alkali-Activated Slag Cements", Advances in Cement Research $15,129-136$. 
[26] Fernández-Jiménez, A., Palomo, A. and Alonso, M. M., (2005), “Alkali activation of fly ashes: mechanisms of reaction Non-Traditional", Cement and Concrete Brno, Czech Republic Ed. V. Bilek and Z. Kersner, Brno University of technology, 1-12.

[27] Fernández-Jiménez, A., Palomo, A. and Revuelta, D. (2009), "Alkali activation of industrial by-products to develop new earth-friendly cements", Proceeding of the 11th International Conference on Non-Conventional Materials And Technologies (NOMAT 2009) 6-9 September 2009, Bath, UK.

[28] Fletscher, R. A., Mac Kenzie, K. J. D., Nicholson, C. L. and Shimada, S. (2005), “The composition range of aluminosilicate geopolymers". J European Ceram. Soc. 25, 1471 1477.

[29] Freidin, C. (2007), "Cementless pressed blocks from waste products of coal-firing power station", Cement and Concrete Research 21, 12-18.

[30] Gasteiger, H. A., Frederick, W. J. and Streisel, R. C. (1992), "Solubility of aluminosilicates in alkaline solutions and a thermodynamic equilibrium model", Ind. Eng. Chem. Res. 31, 1183-1190.

[31] Gourley, J. T. (2003), "Geopolymers; Opportunities for environmentally friendly construction materials", Presented as a keynote paper at; Materials 2003 conference, Adaptive Materials for a Modern Society, Institute of Materials Engineering Australasia, Sydney.

[32] Granizo, M. L., Blanco, M. T. (1998), "Alkaline activation of metakaolin - an isothermal conduction calorimetry study", Journal of thermal analysis and calorimetry 52, 957-965.

[33] Gum S. R., Young B. L., Kyung T. K. and Young S. Ch. (2013), "The mechanical properties of fly ash-based geopolymer concrete with alkaline activators", Construction and Building Materials 47, 409-418.

[34] Guo, X., Shi, H. and Dick, W.A. (2010), "Compressive strength and microstructural characteristics of class C fly ash geopolymer", Cement and Concrete Composites 32, 142147.

[35] Hongling, W., Haihong, L. and Fengyuan, Y. (2005), "Synthesis and mechanical properties of metakaolinite-based geopolymer", Colloids and Surfaces A: Physicochemical and Engineering Aspects 31, 1-6.

[36] Hua, X., and van Deventer, J. S. J. (2003), "The effect of alkali metals on the formation of geopolymeric gels from alkali-feldspars”, Colloids Surf. A: Physiocochem. Eng. Aspects 216, 27-44.

[37] Jambor J. (1990), "Pore structure and strength development of cement composites", Cement and Concrete Research 20, 948-954.

[38] Katz, A. (1997), "Fly-ash blended cement activated by a strong base", Proc. of the 10th int. congress on the chemistry of cement, Goteborg, Vol. 3, additives admixtures characterisation technique, paper 3 ii 083.

[39] Kong D. L. Y. and Sanjayan, J. G. (2008), "Damage behavior of geopolymer composites exposed to elevated temperature", Cement Concrete Compos. 30, 986-991. 
[40] Kong, D. L. Y., Sanjayan, J. G. (2008), "Damage behavior of geopolymer composites exposed to elevated temperature", Cement Concrete Compos. 30, 986-991.

[41] Kong, D. L. Y. and Sanjayan, J. G. (2010 a), "Damage behaviour of geopolymer composites exposed to elevated temperature", Cement and Concrete Composites 30, 986991.

[42] Kong, D. L. Y. and Sanjayan, J. G. (2010 b), "Effect of elevated temeperatures geopolymer paste, mortar and concrete", Cement and Concrete Research 40, 334-339.

[43] Kriven, W. M., Bell, J. and Gordon, M. (2008), "Geopolymer Refractories for the Glass Manufacturing Industry, in 64th Conference on Glass Problems", Ceramic Engineering and Science Proceedings Vol. 25, Issue 1 (ed W. M. Kriven), John Wiley \& Sons, Inc., Hoboken, NJ, USA. doi: 10.1002/9780470294857.ch5

[44] Li, K. L., Huang, G. H., Chen, J., Wang, D. and Tang, X.S. (2005), "Early Mechanical Property and Durability of Geopolymer”, Geopolymer 2005, 117-120.

[45] Lodeiro, G., Palomo, A. and Jiménez, F. (2007), “Alkali-aggregate reaction inactivated fly ash system”, Cement Concrete Res., 37, 175-183.

[46] Marylynn, P. and Kim, F., (2002), "Substudy 7: How Innovation Can Help the Cement Industry Move Toward More Sustainable Practices", Toward a Sustainable Cement Industry, March 2002, An independent Study Commissioned by: World Business Council for Sustainable Development

[47] McLellan, B.C., Williams, R.P., Lay, J., Arie van Riessen, A. and Corder, G.D. (2011), "Costs and carbon emissions for geopolymer pastes in comparison to ordinary portland cement", Journal of Cleaner Production 19, 1080-1090.

[48] Naragaj, T. S. and Zahida Banu T. S. (1996), "Generalization of Abram's law”, Cement and Concrete Research 26, 933-942.

[49] Nicholson, C., Fletcher, R., Miller, N., Stirling, C., Morris, J., Hodges, S., MacKenzie, K. and Schmücker, M. (2005), "Building Innovation through Geopolymer Technology", Chemistry in New Zealand, 10-12.

[50] Nicholson, C.L. and Shimada, S. (2005), "The composition range of aluminosilicate geopolymers", J. Eur. Ceram. Soc 25, 1471-1477.

[51] Palacios, M. (2006), "Efecto de aditivos organicos en las propriedades de los cementos y morteros de escoria activada alcalinamente", $\mathrm{PhD}$ thesis, Universidad Autonoma de Madrid, Spain.

[52] Palacios, M., Banfill, Ph. and Puertas, F.F.G. (2008), "Rheology and Setting of AlkaliActivated Slag Pastes and Mortars: Effect of Organic Admixture”, ACI Materials Journal 105, 140-148.

[53] Palomo, A. and Fernández-Jiménez, A. (2005), "Some main factors influencing the alkali activation of fly ashes Factores", Non-Traditional Cement and Concrete Brno, Czech Republic Ed. V. Bilek and Z. Kersner.

[54] Pandey, B., Kinrade, S. D., Catalan, L. J. (2012), "Effects of carbonation on the leachability and compressive strength of cement-solidified and geopolymer-solidified synthetic metal wastes", J Environ Manage. 30, 59-67. 
[55] Perera D. S. and Trautman, R. L. (2006) "Geopolymers with the potential for use as refractory castables”, Adv. Technol. Mat. Mat. Proc. J. 2, 187-189.

[56] Phair, J.W., and Van Deventer, J. S. J. (2001), "Effect of silicate activator pH on the leaching and material characteristics of waste-based inorganic polymers", Minerals Engineering 14, 289-304.

[57] $\mathrm{Pu}, \mathrm{X}$. (1999), "Investigation on pozzolanic effect of mineral additives in cement and concrete by specific strength index", Cement and Concrete Research 29, 951-955.

[58] Qing-Hua, C. and Sarkar, S. L. (1994), "A Study of Rheological and Mechanical Properties of Mixed Alkali Activated Slag Pastes", Advanced Cement Based Materials 1, 178-184.

[59] Rodríguez, E. D., Susan, A., Bernal, J. L., Provis, L., Paya, J., José, M., Monzo, M. and Borrachero, M. A. (2013), "Effect of nanosilica-based activators on the performance of an alkali-activated fly ash binder", Cement \& Concrete Composites 35, 1-11.

[60] Roessler, M. and Odler, I. (1985), "Investigation on the relationship between porosity, structure and strength of hydrated Portland cement pastes. I. Effect of porosity", Cement and Concrete Research 15, 320-330.

[61] Rowles, M. and Connor, B. O. (2003), "Chemical optimisation of the compressive strength of aluminosilicate geopolymers synthesised by sodium silicate activation of metakaolinite", J. Mater. Chem.13, 1161-1165.

[62] Roy, D. M., Gouda, G. R. and Borovsky, A. (1972), "Very high strength cement pastes prepared by hot pressing and other high pressure techniques", Cement and Concrete Research, 2, 807-820.

[63] Roy D. M. and Gouda, G. R. (1973), "High strength generation of cement pastes", Cement and Concrete Research 3, 349-366.

[64] Schulze, J. (1999), "Influence of water-cement ratio and cement content on the properties of polymer modified mortars", Cement and Concrete Research 29, 909-915.

[65] Shao-Dong Wang, Xin-Cheng Pu, Scrivener, K. L. and Pratt P. L. (1995), "Alkaliactivated slag cement and concrete a review of properties and problems", Advances in Cement Research, 7, 27, 93-102.

[66] Shi, C., Krivenco, P. V. and Roy, D. (2006), "Alkali-activated cements and concretes" Ed. Taylor \& Francis.

[67] Temuujin, J., van Riessena, A. and MacKenzie, K. J. D. (2010), "Preparation and characterisation of fly ash based geopolymer mortars. Construction and Building Materials 24, 1906-1910.

[68] Thokchom, S., Ghosh, P. and Ghosh, S. (2010), "Performance of Fly ash Based Geopolymer Mortars in Sulphate Solution”, J. Eng. Tech. Rev. 3, 36-40.

[69] Van Jaarsveld, J. G., van Deventer, J. S. J., Lukey, G. C. (2002), "The effect of composition and temperature on the properties of fly ash- and kaolinite-based geopolymers", Chemical Engineering Journal 89, 63-73. 
[70] Van Jaarsveld, J. G. S., van Deventer, J. S. J. and Lukey, G. C. (2003), "The characterization of source materials in fly ash-based geopolymers", Mater. Lett. 57, 1272 1280.

[71] Weil, M., Jeske, U., Dombrowski, K. and Buchwald, A. (2007), "Sustainable Design of Geopolymers-Evaluation of Raw Materials by the Integration of Economic and Environmental Aspects in the Early Phases of Material Development. In Advances in Life Cycle Engineering for Sustainable Manufacturing Businesses", Proceedings of the 14th CIRP Conference on Life Cycle Engineering, Waseda University, Tokyo, 279-283.

[72] $\mathrm{Xu}, \mathrm{H}$. and van Deventer, J. S. J. (2000), "The geopolymerisation of alumino-silicate minerals", Int. J. Miner. Process 59, 247-266.

[73] Xu, H. (2002), "Geopolymerisation of aluminosilicate minerals", PhD thesis, Department of Chemical Engineering, University of Melbourne, Australia.

[74] Zhang, G. and Gambrell, R. P. (2010), "Synthesis, characterization and mechanical properties of red mud based geopolymers", Trans, Res, Fecord, 2164, 1-9.

[75] Zhongzi, X., Mingshu, T. and Beaudoin, J. J. (1993 b), "Relation between composition, structure and mechanical properties of very low porosity cementitious systems", Cement and Concrete Research 23,187-195.

[76] Zhongzi, X., Yongmei, D., Xuequan and W., Mingshu, T. (1993 a), "Influence of various hydraulic binders of performance of very low porosity cementitious systems", Cement and Concrete Research 23, 462-470.

[77] Živica, V. (1993), "Alkali-silicate admixture for cement composites incorporating pozzolana or blast furnace slag", Cement and Concrete Research 23, 1215-1222.

[78] Živica, V. (1999), "Possibilities of a novel use of silica fume in mineral binding systems", Construction and Building Materials 13, 271-277.

[79] Živica, V. (2004), "High effective silica fume alkali activator", Bulletin of Materials Science 27, 179-182.

[80] Zivica, V., Bagel, L. and Kuliffayova, M. (2010), "High strength alkali-acivated slag paste", Building Research Journal 58, 187-197.

[81] Živica, V., Balkovic, S. and Drabik, M. (2011), "Properties of metakaolin geopolymer hardened paste prepared by high-pressure compaction", Construction and Building Materials 25, 2206-2213.

[82] Živica, V. and Križma, M. (2013), “Acid-resistant slag cement”, Magazine of concrete research 65, 1073-1080.

[83] Zivica, V., Palou, M. T., Ifka, T. and Bagel, L. (2014), "High strength metahalloysite based geopolymer", Composites, Part B: Engineering 57, 155-165. 